\title{
Religiones políticas y héroes patrios
}

\section{Jesús Casquete}

Universidad del País Vasco/Euskal Heriko Unibertsitatea

Facultad de Ciencias Sociales y de la Comunicación

jesus.casquete@ehu.es

\section{Resumen}

El presente trabajo desvela el significado sociológico de la acción del héroe nacional que renace y que, pro patria mori, reinventa el camino ya transitado por el mártir clásico en esta nueva pirámide de sacrificio que es el Estado nacional, ejemplificando a aquél con referencias históricas tomadas del nazismo y del sionismo.

Palabras clave: mártir, héroe, romanticismo de la muerte, nazismo y sionismo.

\section{Abstract. Political Religions and National Heroes}

This paper takes into account the sociological meaning of the national hero as a re-born that, pro patria mori, re-invents the pathway already walked by the classic martyr within a new pyramid of sacrifice represented by the national State, explanation tailored with historical references taken from Nazism and sionism.

Key words: martyr, hero, romanticism of death, nazism and sionism.

\section{Sumario \\ 1. La construcción del héroe nacional Bibliografía}

2. Dos ejemplos

\section{La construcción del héroe nacional}

La religión, sostiene el filósofo italiano Agamben, consiste en sustraer cosas, lugares, animales o personas al uso común y transferirlas a una esfera separada (2005: 96). Cuando la política es objeto de sacralización hasta definir el fin y el significado de la existencia humana y colectiva, entonces hablamos de una religión política. El partido, la clase, el Estado, la raza, el movimiento o la nación, según el caso, son elevados a la categoría de entidades políticas trascendentes e indiscutibles que figuran en el centro de un sistema más o menos sofisticado de creencias, mitos, valores, mandamientos, rituales y símbolos que son vividos e interpretados por la comunidad de creyentes cuales objetos de fe y culto. Entre los creyentes más fervientes, no falta quien se muestra dis- 
puesto a sacrificar su vida por ellos. Una religión política, entonces, sería «la sacralización de un sistema político fundado sobre el monopolio irrevocable del poder, el monismo ideológico y la subordinación obligatoria e incondicionada del individuo y la colectividad a sus códigos de mandamiento» (Gentile, 2001: XIII-XIV; 2005: 29). Los ejemplos clásicos de religiones políticas son el nacionalsocialismo, el fascismo y el comunismo soviético. Algunos nacionalismos contemporáneos que sacralizan a la patria hasta disolver al individuo en la comunidad también se dejan interpretar desde este punto de vista.

Las religiones políticas se caracterizarían, pues, por un conjunto dogmático y sacralizado de naturaleza política que viene acompañado de un despliegue simbólico-ritual a su alrededor. La dimensión ritual del fenómeno religioso resulta imprescindible, como supo ver Durkheim (2001; orig. 1912), para preservar las fronteras sistémicas (esto es, su identidad colectiva) de la comunidad creyente. Corresponde a la esencia de las religiones, políticas o "convencionales», el proceder a la sacralización de la dimensión espacio-temporal, es decir, a la atribución de un estatus sagrado a fechas y lugares para resaltar su discontinuidad con respecto al espacio y al tiempo ordinarios, profanos (Eliade, 1998). En lo que resta de trabajo, centraremos nuestra atención en el calendario conmemorativo, o conmemograma, de las religiones políticas, esto es, en el tiempo litúrgico de aquellas fechas señaladas en rojo en la agenda de estos movimientos ideológicos. En concreto, nos ocupará la figura del héroe (pues casi siempre son varones) caído de forma trágica por la Causa de la patria en tanto que uno de los ejes de las celebraciones sujetas a calendario de las religiones políticas ${ }^{1}$.

El objeto de la conmemoración («la acción de hablar o escribir sobre los recuerdos»; Fentress y Wickham, 2003: 14. Énfasis en el original) sobre el que versará nuestra investigación será, decíamos, el héroe. En tanto que tipo ideal, el héroe designa al valeroso luchador que pugna por imponer un cierto orden en medio del caos y la crisis, sea ésta de naturaleza social, económica, política o cultural ${ }^{2}$. Con él, gracias a él, el futuro no será nunca más penumbroso como el pasado, sino inevitablemente mejor, una nueva época de luces y gloria. Lo que aparta al héroe del individuo corriente es la comisión de un acto o la toma de una decisión que, siempre a ojos de sus admiradores, resultan necesarios, provechosos y modélicos para la comunidad de referencia, al tiempo que considerablemente comprometidos y arriesgados de llevar a cabo habida cuenta de

1. No obstante, el culto a los héroes caídos por la patria no agota las festividades de los calendarios de las religiones políticas. Así, durante el infausto periodo nacionalsocialista, el calendario festivo incluía fiestas paganas (por ejemplo: el solsticio de invierno cada 21 de diciembre), otras vampirizadas al movimiento obrero (1 de mayo), ligadas la culto a la personalidad (cumpleaños de Hitler el 20 de abril), fechas señaladas en el decurso del movimiento (proclamación del programa del partido el 24 de febrero; toma del poder el 30 de enero; día del partido en la primera quincena de septiembre), etc. Ver: Vondung, 1971.

2. En las consideraciones que siguen acerca de la figura heroica, me ha resultado extremadamente útil el tratamiento que S. Behrenbeck (1996) hace de los mitos y rituales del periodo nacionalsocialista. Véase, asimismo: Naumann, 1984. 
la amenaza que su empresa comporta. Son precisamente el grado de complejidad y/o compromiso requeridos para su puesta en práctica los factores que hacen que el acto heroico no esté al alcance de cualquiera, por lo que despiertan una indisimulada admiración entre sus adictos, privados como se encuentran en su mayoría de saber, de poder o, sencillamente, de querer replicar las acciones ejemplares del héroe. Y no resultan accesibles a todo el mundo, porque sólo los seres excepcionales o tocados por la providencia disponen de los atributos de vitalidad, compromiso, altruismo, sacrificio, abnegación, fuerza de voluntad, valor, entrega, ilusión, resolución y desprecio por la muerte que distancian sin remedio al héroe del común de los mortales.

La muerte del héroe nacional constituye una pieza fundamental en el desarrollo de la idea de la nación. Bien sea en el curso de una guerra civil, de una guerra interestatal o de una revolución, podemos contemplar al héroe caído en combate como la versión secularizada del mártir caído por Dios ${ }^{3}$.

3. No deja de resultar extremadamente sintomática la proliferación, a la vez que secularización de la retórica épica y martirial en las sociedades occidentales, posmodernas ellas, desde la Primera Guerra Mundial hasta nuestros días. Claro que este uso inflacionario no es, ni mucho menos, privativo de estas sociedades. También en otros contextos sociopolíticos y culturales se asiste a un vertiginoso incremento de la apelación a posturas martiriales y heroicas. Así, los 19 terroristas islamistas que perpetraron los atentados del 11 de septiembre de 2001 se consideraban a sí mismos y son considerados por sus admiradores como mártires, igual que ocurría con sus correligionarios que participaron en la matanza del 11 de marzo de 2004 y que se inmolaron poco después en Leganés tras ser cercados por la policía, «los primeros mártires de Europa» (El País, 3 de octubre de 2004, p. 27) en la Guerra Santa contra los infieles. En el caso de los musulmanes, Dios recompensa al soldado de Alá con el Paraíso: "Gracias a sus méritos y a su sacrificio, el mártir es aligerado de su culpa, el fuego depurador le condona sus pecados, y se le ahorra el día del juicio. Le es permitido ocupar el más alto peldaño en el Paraíso y estar al lado del trono de Dios [...] Su sacrificio tiene poder expiatorio" (TRE, 22, 199; citado en Maier, 2004: 119). Sin embargo, no estará de más recordar que el sacrificio de vidas humanas no es en absoluto una tradición asentada en el mundo musulmán. Por el contrario, la idea de que la práctica del terrorismo contra civiles desarmados abrirá las puertas del Paraíso por la entrada reservada a los mártires, es una invención reciente que habría horrorizado a los musulmanes en el pasado y que aún estremece a la mayoría hoy (Buruma y Margalit, 2004: 68-9).

Por otro lado, conviene subrayar que la retórica heroica y martirial no es ni mucho menos exclusiva del mundo fundamentalista islámico. Así, por ejemplo, Abimael Guzmán y Elena Iparraguirre, líderes de la organización terrorista peruana Sendero Luminoso, vieron llegar a término sus privilegios carcelarios después de que desafiaran al tribunal que les juzgaba lanzando vivas a la lucha armada y a sus «héroes» (El País, 26 de noviembre de 2004). Por no hacer interminable la lista, mencionaremos un último ejemplo de un contexto sociopolítico, cultural y geográfico radicalmente diferente a los considerados hasta ahora. En su prédica ante los aproximadamente 3.000 nostálgicos del régimen nacionalsocialista congregados en la Alexanderplatz de Berlín con motivo del sesenta aniversario de la capitulación alemana en la Segunda Guerra Mundial, el secretario general del Partido Nacionaldemocrático Alemán (NPD), Udo Voigt, poco antes de reiterar su orgullo patrio, declaraba: «Recordamos a las víctimas del terror de las bombas aliadas, a los soldados de la Wehrmacht, la Luftwaffe, la Marina y de las SS que murieron heroicamente o tras la guerra en prisiones aliadas, torturados y asesinados» ("Ansprache des Parteivorsitzendes Udo Voigt zur Demonstration in Berlin zum 8. Mai 2005», www.npd.de, 10 de mayo de 2005. Cursiva mía). 
Etimológicamente derivado del griego mártys ('testigo'), el término mártir se refiere a aquella persona que muere o padece sobremanera en defensa de sus ideales, con frecuencia por negarse a renunciar a ellos. Sin ofrecer resistencia alguna, soporta estoicamente el sufrimiento que el destino le depara (Sofsky, 2004: 9-10). Además, a diferencia del héroe, que concede una gran relevancia a la correcta interpretación de su acto, el mártir se muestra relativamente despreocupado por las consecuencias imprevistas de su determinación: "Mientras que el sentido del martirio no depende de lo que ocurre en el mundo después, el sentido del heroísmo sí» (Beriain, 2007).

Desde sus mismos textos doctrinales, la tradición cristiana es rica en el testimonio de la fortaleza de la $\mathrm{fe}^{4}$. Porque es precisamente la fe el valor primario de la militancia del héroe por la Causa, su principal cualidad, por encima de otros atributos más o menos circunstanciales como la cultura, la belleza o la inteligencia. Por ceñirnos al Nuevo Testamento, en varios evangelios se recogen invitaciones al martirio y a la renuncia absoluta, vida propia incluida, como testimonio supremo del amor a Jesús: «El que quiera conservar la vida, la perderá, y el que la pierda por mí, la conservará» (Mt. 10,37; en términos similares, véase Mc. 8,34; Lc. 14,26). Los mártires del cristianismo, empezando por Policarpo de Esmirna en el año 155 dC, cumplirían, de forma latente o manifiesta, la función de reforzar y consolidar la identidad grupal de los primeros cristianos. Es en este sentido que podemos hablar, por paradójico que parezca, del valor integrador de la muerte. Tanto es así que, cuando de forjar argamasa social se trata, "cuantos más [mártires] hubiese, mejor; y cuando no había ninguno, entonces se elaboraban, al final de modo masivo» (Liebs, 2002: 46). Así hasta superar los 165.000 mártires, que son los que, según algunas estimaciones, figuraban en el cuadro martiriológico del cristianismo en el año 2000 (Seidensticker, 2002: 137). Es este mismo autor quien subraya que el concepto de mártir del islam bebe de forma determinante del cristianismo. Para defender su argumento, este especialista esgrime las siguientes concomitancias entre una y otra religión monoteísta en lo que hace referencia a la consideración del mártir. En primer lugar, en ambas religiones el alma del mártir está llamada a ocupar un lugar privilegiado en el Cielo o en el Paraíso. Y, en segundo lugar, la enseñanza del profeta Mahoma de acuerdo con la cual el impulso primero del mártir no es la búsqueda de la gloria, sino el deseo de expandir la palabra de Dios, encontraría su contrapartida en la sentencia agustiniana según la cual «martyrium non fecit poena, sed causa» (ibídem: 146).

Si hacemos abstracción del hecho de que el soldado muere armas en mano, en tanto que el mártir cristiano se ofrece a sus ejecutores sin presentar resistencia como mejor modo de participar del sacrificio de Cristo (lo cual, admitido, no es poco suponer), el devenir histórico atestigua la hipótesis de una transferencia del sacrificio cristiano por Dios al sacrificio por la patria. ¿Cuándo exac-

4. Como también ocurre con la tradición judía tradicional, donde el equivalente del mártir cristiano viene a ser el Kiddush ha-Shem, i la islámica, con el Shahid (Bowker, 1997). 
tamente se habría producido dicha transferencia? El medievalista Ernst Kantorowicz (1965) sostiene que fue en el curso del siglo XIII cuando tuvo lugar una redefinición del «estado» como corpus mysticum, consideración de la que hasta entonces tan sólo había disfrutado la Iglesia. Las consecuencias inmediatas de tal interpretación no van a ser menores. A partir de entonces, toda una tradición teológica va a equiparar en valor la muerte o el sufrimiento del cruzado por la causa de Dios con la muerte en defensa de los colores patrios (pro patria mori) en lo que supone, tal y como apuntábamos, un ejercicio de transferencia de esquemas religiosos al ámbito estrictamente político-secular. Ya no será posible establecer una nítida línea de demarcación entre ambos tipos ideales de muerte sacrificial. Ha nacido la figura del héroe-mártir, al que, por economía del lenguaje, aquí seguiremos denominando «héroe». Su momento de máximo «esplendor» (si es que tiene sentido hablar en esos términos) tardará todavía unos cuantos siglos en llegar, y lo hará de la mano de los movimientos totalitarios del siglo XX, en particular del nacionalsocialismo y del fascismo.

No son raras las instancias en las que el comportamiento épico colisiona frontalmente con el código moral establecido y ampliamente compartido en una sociedad liberal, por ejemplo cuando de sustraer vidas ajenas se trata. No importa. El héroe patrio se mueve más allá de la dicotomía del bien y del mal. Su definición de lo necesario en una determinada situación le impele a comportarse de modo unilateral, extremo y apasionado hasta la brutalidad, no dudando incluso en utilizar a los demás (sus vidas incluidas) como instrumento en aras de la consecución del fin último anhelado, llámese la supervivencia del grupo a quien representa o el mantenimiento de su orden: «lleva a cabo el más alto acto moral - el sacrificio de su propia persona - con un gesto de crueldad brutal» (Sofsky, 2004: 9). El uso de la violencia es un rasgo frecuentemente asociado al heroísmo y, desde luego, inextricablemente vinculado a un tipo particular de héroe, el revolucionario (Naumann, 1984: 90).

Por lo general, la contribución más admirada del héroe consiste en que arriesga su vida a favor de la causa, llámese ésta Dios, señor, república, imperio, nación, estado, clase o patria. No arredrarse ante la muerte (ni la propia ni la ajena) es uno de los rasgos prototípicos del héroe en tanto que tipo ideal, sin duda la piedra de toque del romanticismo de la muerte en que, con relativa frecuencia, se ha convertido su culto. En este sentido, lo que distingue al mortal ordinario del héroe extraordinario es la disposición que éste último muestra por sacrificar desinteresadamente al servicio de la causa su tiempo, su mundo afectivo, su carrera profesional, sus bienes materiales y, ante todo y sobre todo, su propia existencia ${ }^{5}$. Sólo acceden al estatus de héroes aquéllos que llegan tan lejos como para ofrendar su vida, para «confesar su fe con la sangre» ${ }^{6}$. Es, enton-

5. Los héroes serían, extrapolando lo que el escritor Javier Marías afirma refiriéndose a lo efímero de la vida profesional de los futbolistas, "gente con apoteosis breve, y el recuerdo largo". Véase: J. MARÍAS, «Y el recuerdo largo», EPS, domingo 12 de febrero de 2006, p. 110.

6. Esta ilustrativa expresión está recogida de los cometidos que el Partido Fascista Italiano esperaba de sus militantes. Según el Gran Consiglio de dicho partido, creado y presidido 
ces, un dato consustancial a la esencia del héroe el anteponer la perpetuación de la comunidad al miedo a la muerte propia, ni qué decir tiene que también a la comisión de actos mortíferos ${ }^{7}$. La muerte como sujeto y objeto es una acompañante indisociable de la figura heroica en un círculo con frecuencia infernal. Pierre Vilar se hace eco de forma precisa de lo diabólico que corren el riesgo de tornarse las posturas sacrificiales por la patria. Afirma el reputado historiador francés: «en cierto sentido, es satisfactorio para nuestra sensibilidad que "morir por la patria" sea glorioso y "matar por la patria" generalmente inconfesable. Pero lo uno implica lo otro. Peligrosamente» (2004: 80).

Para erigirse en tal, el héroe precisa de una contraparte, de un antihéroe que encarne el principio del mal, la impureza, la desgracia y la destrucción con quien se batirá hasta las últimas consecuencias en representación del grupo amenazado. Aunque sólo sea para mantener ocupados a los héroes, una sociedad precisa de villanos. En la medida que salga airoso de una confrontación por definición asimétrica con el adversario (pues siempre se presenta en marcada desigualdad de condiciones; de lo contrario la epopeya se difumina, se vulgariza y se devalúa), los salvados mostrarán su agradecimiento y veneración al héroe elevándolo a la categoría de modelo. En el caso de que sacrifique su vida en el curso de un acto redentor, entonces el héroe-mártir se habrá hecho acreedor de un recuerdo imperecedero, por glorioso, que permanecerá grabado para la posteridad en la memoria colectiva de la comunidad a la que dice representar. Habrá protagonizado una "hermosa muerte», que era como calificaban los atenienses al «muero para no morir» (Lyotard, 1988: 120). Se habrá convertido, en otras palabras, en una hierofanía (del griego hieros = 'sagrado' y phainomai = 'manifestarse' —Eliade, 1998: 14), en un mito imperecedero capaz de marcar el rumbo e imponer su estela sobre las generaciones venideras como una herencia colectiva de referencia a quien emular según el principio do ut des. Aplicado al caso que nos ocupa, este principio de reciprocidad invita a todos los miembros de la subcomunidad a compartir los costes de una acción en interés de la comunidad y a no dejar, cual (mundanos) free-riders, que sean unos pocos, precisamente los héroes, sus paganos exclusivos. Es decir, que el motor y la motivación principal que induce al héroe a la acción no ha

por Mussolini, los fascistas debían ser «soldados listos en cualquier momento, dentro y fuera de las fronteras, singularmente o en masa, a confesar su fe con la sangre, sin discutir las órdenes provenientes de las jerarquías necesarias" (Il Gran Consiglio nei primi dieci anni dell'era fascista, Roma, 1933, p. 24. Citado en Gentile, 2004: 187).

7. El hecho de que el héroe-mártir haga frente a la muerte, no significa que no le infunda miedo; únicamente que lo ha conseguido dominar. En sus memorias de la Primera Guerra Mundial, Ernst Jünger, oficial del ejército alemán herido en varias ocasiones en primera línea del frente, aclara este extremo con lucidez: «La gente que permanece allá en la patria nos mira a veces como si fuéramos unos tipos tan valerosos que considerásemos que nuestra vida no vale un comino; pero he vivido entre guerreros el tiempo suficiente para saber que el hombre sin miedo no existe. Además, si el miedo no existiera, carecería de sentido el valor; el miedo es la sombra oscura contra cuyo trasfondo aparece más multicolor y atrayente el riesgo" (2005: 310). 
de ser jamás el de dar para recibir, planteamiento en esencia egoísta, sino más bien el de dar para invitar a otros para que también den en virtud del ejemplo educativo difuso de una conducta entendida como ejemplarizante por una comunidad de recuerdo determinada.

Una vida consagrada al sacrificio merece ser reconocida como es debido. En parte como modo de reconocimiento colectivo por el sobrecoste que asumen unos pocos, nace el culto a los héroes caídos, porque los héroes, o están muertos, o lo son en precario, esto es, sin garantía alguna de alcanzar la eternidad. El estatus del héroe vivo puede ensombrecerse de la noche a la mañana; el del muerto consolidado en su condición épica, por el contrario, más raramente, si acaso a raíz de cambios de régimen y de la implantación subsiguiente de un nuevo elenco de artefactos mnemónicos, callejero, estatuaria y calendarios incluidos, pues tal acostumbra a ser una de las primeras medidas que adopta todo régimen cuando reemplaza a otro comenzando así su andadura. A este respecto, la idea de deuda para con el héroe caído se erige en el correlato de la de legado. La comunidad de referencia venera al mártir caído, porque, al ver escrita en él una parte de su identidad, se considera en el deber de hacerle justicia mediante su exaltación y recuerdo. Ricoeur insiste en este aspecto: «el deber de memoria no se limita a guardar la huella material, escrituaria u otra, de los hechos pasados, sino que cultiva el sentimiento de estar obligados a estos otros de los que afirmaremos más tarde que ya no están pero que estuvieron» (2003: 121). Deuda perpetua, pues, como sentimiento funcional para garantizar la siempre trabajosa integración grupal.

Además de contarse en el reino de los muertos, otro tropo recurrente de la figura épica, sobre todo en los movimientos revolucionarios y en los nacionalistas con connotaciones religiosas, tiene que ver con una narrativa de «los pocos contra los muchos». El carácter vanguardista y desinteresado del héroe queda bien retratado en su obstinación por perseverar en la causa, por más que se vea inmerso en un mar de dificultades y peligros. No importa el número de fieles que suscriben los postulados del movimiento; lo determinante es el grado de convicción del héroe y el mostrarse impermeable a las apelaciones más o menos benévolas para que rectifiquen. Claro que la construcción social del mito político (y ahora invadimos el terreno de la historiografía) no tiene por qué mostrarse respetuosa con los hechos históricos. Más todavía: a menudo no lo es en absoluto. Por lo general, las elites encargadas de dar forma y contenido al mito proceden al limado de sus aristas menos funcionales, a su depuración, a su lustre, al falseamiento descarado incluso. Mencionaremos varios ejemplos que ilustran esta pauta universal en la construcción de los mitos políticos.

\section{Dos ejemplos}

El primer ejemplo que traemos a colación procede del nacionalismo israelí. Se trata del mito de Tel Hai, uno de los cuatro asentamientos sionistas en la Galilea superior donde, en 1920, tuvo lugar una encarnizada batalla contra los árabes. En aquel momento, se estima en unos 57.000 los judíos que poblaban 
Palestina. El 1 de marzo de aquel año seis colonos encontraron su muerte en la defensa del asentamiento, incluido su responsable militar, Yosef Trumpeldor, originario de Rusia y veterano de la guerra ruso-japonesa, así como de la Gran Guerra, en la que organizó una unidad judía bajo mando británico, la Zion Mule Corps. Las estimaciones de la época no son en exceso precisas a la hora de proporcionar un número de sitiadores, puesto que ofrecen cifras que oscilan entre los 150 y varios centenares de árabes frente a un puñado de judíos. En todo caso, unos pocos frente a muchos. La batalla de Tel Hai se celebra a día de hoy en Israel en el marco de las festividades dedicadas al recuerdo de los héroes, y el responsable de su defensa, Trumpeldor, es conmemorado como el primer héroe nacional de la sociedad judía en Palestina, la primera muestra de la disposición heroica a dar la vida por la patria que contrasta con el judío del exilio, resignado a su papel secular de víctima propiciatoria. A él se atribuye un eslogan nacional en el Israel contemporáneo, el de que «es bueno morir por la patria». Cuando el doctor Gerry, un médico norteamericano que llevaba dos semanas en el país, le inquirió por su estado en su lecho de muerte, Trumpeldor supuestamente le respondió en su hebreo (¿o fue en su ruso materno?; Gerry tampoco dominaba el idioma) aprendido a duras penas: "No se preocupe, merece la pena morir por la patria». Son muchos los israelíes que hoy en día dudan de la veracidad de sus palabras, incluso del idioma en que las pronunció, y que se inclinan por la «fabricación» del mito de Trumpeldor ${ }^{8}$. Desde aquellos días, Trumpeldor ha sido presentado como modelo en que mirarse las nuevas generaciones primero judeo-palestinas e, inmediatamente después, las israelíes. Yosef Klausner, tío abuelo del escritor Amos Oz, propondría, unos años después de los sucesos de Tel Hai, la terapia para superar esta situación, que consistiría en «darles a las jóvenes generaciones una nueva educación, [en] investirlas de un espíritu heroico» (Oz, 2005: 92. Énfasis en el original). Trumpeldor servirá a la perfección a tal propósito pedagógico. Es más: será el troquel que permitirá afirmar al nacionalismo israelí, como declara el personaje de la novela de $\mathrm{Oz}$, que «ganasteis en esa y en todas las guerras, pocos contra muchos» $(\mathrm{Oz}, 1998: 205)$.

Un segundo ejemplo que quisiéramos traer a colación al respecto de la retórica de los pocos frente a los muchos la encontramos en el mito de Horst Wessel, el joven cuadro dirigente de las SA nazis fallecido en 1930 en Berlín víctima de un ataque comunista armado. Era el caído número 53 de las filas de las SA en unos años, los de la República de Weimar, en que los enfrentamientos mortales entre facciones izquierdistas y nazis estaban a la orden del día. Parece ser que el gran propagandista y manipulador de las emociones de masas que fue Goebbels había conocido personalmente al finado. Por ello, pero sobre todo porque se percató de las posibilidades que se presentaban para manufacturar un mito político, Goebbels publicó varias notas necrológicas en el perió-

8. Para una descripción de los acontecimientos, véase Y. Zerubavel, 1995, p. 39-47. Para su lectura actual en Israel, p. 159-60. Asimismo, véase: Zertal, 2005, cap. 1. 
dico que él mismo tan hábilmente dirigía en Berlín desde 1927, el Angriff. Goebbels se preocupó de presentar la muerte de Wessel como la consecuencia directa de su pertenencia al «movimiento». Se sacrificó por su patria, afirma Goebbels; predicó el evangelio nazi en el desierto; se trataba de un "cristosocialista", de un Mesías. Lo que en ningún momento menciona el por aquel entonces máximo responsable del partido nacionalsocialista en la capital alemana, es que su asesino fue un proxeneta que había "tutelado» a la mujer de la que se había enamorado perdidamente Wessel y con la que se había mudado a un barrio obrero de Berlin, a Friedrichshain; ni que el crimen tenía evidentes connotaciones pasionales en lugar de políticas. En rigor, no se puede recriminar a Goebbels que mintiese en sus notas hagiográficas sobre Wessel; sólo que no proporcionase toda la información que rodeó al caso, lo cual tiene consecuencias igual de falseadoras de la realidad que la mentira. Estos datos, que podrían deslustrar el mito, son ocultados deliberadamente. En su lugar, se destaca el altruismo de Wessel, quien no había dudado de adentrarse en territorio enemigo, nada menos que un barrio dominado por las organizaciones obreras, para predicar el evangelio racista y ultranacionalista en que se resumía la ideología nazi. Uno de esos barrios «rojos» en los que se sentía incómodo hasta el todopoderoso arquitecto y ministro del régimen Albert Speer: «En aquellos sectores, las tropas nacionalsocialistas habitaban en sótanos que más bien parecían agujeros y llevaban una existencia de perseguidos» (2001: 45) ${ }^{9}$; donde, como escribió en 1931 un periodista catalán testigo de excepción, «la "puñalada trapera” y el balazo a quemarropa están a la orden del día» (Xammar: 2005: 50).

Desde que la nación, el estado o la patria fueron investidos de un carácter sagrado por diferentes religiones políticas, nacionalismos iliberales incluidos, los héroes han desempeñado un papel de capital importancia en su desarrollo. En tanto que factores de cohesión grupal y modelos a imitar, los héroes han sido sometidos a un proceso de construcción social que no ha merecido toda la atención que se merecen por parte de los sociólogos. En este trabajo hemos intentado presentar algunas claves para su interpretación, así como algunos mecanismos de su «troquelado» social.

\section{Bibliografía}

Agamben, Giorgio (2005). Profanaciones. Barcelona: Anagrama.

BAIRD, Jay W. (1990). To Die for Germany. Nazis in the Nazi Pantheon. Bloomington and Indianapolis: Indiana University Press.

BeHRenbeCK, Sabine (1996). Der Kult um die toten Helden. Nationalsozialistische Mythen, Riten und Symbole. Greifswald: SH.

BERIAIN, Josetxo (2007). "Chivo expiatorio-mártir, héroe nacional y suicida-bomba: las metamorfosis sin fin de la violencia colectiva». Papers, 2007, núm. 84, p. 99-128. En este mismo número.

9. Sobre los pormenores del mito de Horst Wessel y su proceso de construcción social, remitimos a: Baird, 1990, cap. 4; Behrenbeck, 1996, p. 134-48, y Sala, 2003, p. 415-20. 
BOWKeR, John (ed.) (1997). The Oxford Dictionary of World Religions. Oxford: Oxford University Press.

Buruma, Ian; Margalit, Avishai (2004). Occidentalism. The West in the Eyes of its Enemies. Londres: Penguin.

DurKheIm, Emile (2001) (1912). The Elementary Forms of Religious Life. Oxford: Oxford University Press.

EliADE, Mircea (1998). Lo sagrado y lo profano. Paidós: Barcelona.

Fentress, James; WiCKHAM, Chris (2003). Memoria social. Madrid: Cátedra y Universitat de València.

GENTILE, Emilio (2001). Le religioni della politica. Fra democracia e totalitarismi. RomaBari: Laterza.

GeNTILE, Emilio (2004). Fascismo. Historia e interpretación. Madrid: Alianza.

Gentile, Emilio (2005). «Political Religión: A Concept and its Critics: A Critical Survey». Totalitarian Movements and Political Religions, vol. 6 (1), junio: 19-32. JÜNGER, Ernst (2005). Tempestades de acero. Barcelona: Tusquets.

Kantorowicz, Ernst (1965). «Pro Patria Mori in Medieval Political Thought». En: E. Kantorowicz. Selected Studies. Locus Valley, Nueva York: J. J. Augustin.

LIEBS, Detlef (2002). «Umwidmung. Nutzung der Justiz zur Werbung für die Sache ihrer Opfer in den Märtyrerprozessen der frühen Christen». En: Walter AMELING (ed.). Märtyrer und Märtyrerakten. Wiesbaden: Franz Steiner.

LYOTARD, Jean-François (1988). La diferencia. Barcelona: Gedisa.

MaIER, Hans (2004). Das Doppelgesicht des Religiösen. Religion-Gewalt-Politik. Friburgo: Herder.

NAUmAnN, Michael (1984). Strukturwandel des Heroismus. Vom sakralen zum revolutionären Heldentum. Königstein: Athenäum.

Oz, Amos (1998). No digas noche. Madrid: Siruela.

Oz, Amos (2005). Una historia de amor y oscuridad. Madrid: Siruela.

Ricoeur, Paul (2003). La memoria, la historia, el olvido. Madrid: Trotta.

SALa Rose, Rosa (2003). Diccionario crítico de mitos y simbolos del nazismo. Barcelona: El Acantilado.

SEIDENSTICKER, Tilman (2002). «Die Transformation des christlichen Märtyrerbegriffs im Islam». En: Walter AMELING (ed.). Märtyrer und Märtyrerakten. Wiesbaden: Franz Steiner.

SOFSKY, Wolfgang (2004). Tiempos de horror. Amor, violencia, guerra. Madrid: Siglo XXI.

SPEER, Albert (2001). Memorias. Barcelona: El Acantilado.

VILAR, Pierre (2004). Memoria, historia e historiadores. Granada: Universidad de Granada.

Vondung, Klaus (1971). Magie und Manipulation. Ideologischer Kult und politische Religion des Nationalsozialismus. Göttingen: Vandehoeck \& Rupprecht.

XAMMAR, Eugenio (2005). Crónicas desde Berlín (1930-1936). Barcelona: El Acantilado. ZERTAL, Idith (2005). Israel's Holocaust and the Politics of Nationhood. Cambridge: Cambridge University Press.

Zerubavel, Yael (1995). Recovered Roots. Collective Memory and the Making of the Israeli National Tradition. Chicago: The University of Chicago Press. 